\title{
ANTROPONIME CU CONSOANA LABIALĂ INIȚIALĂ [P] PALATALIZATĂ
}

\author{
TEODOR OANCĂ
}

Palatalizarea consoanelor labiale în limba română a reținut atenția unui însemnat număr de lingvişti români şi străini (cf. Ionică, 1973, p. 79-98), care au stabilit distribuția în teritoriul dacoromân a acestui fenomen fonetic, precum şi diferitele sale stadii de manifestare. În sprijinul acestei cercetări s-au aflat şi atlasele lingvistice. Pentru urmărirea palatalizării consoanei $[\mathrm{p}]$, pe care o avem în vedere, în atenția cercetătorilor au stat apelative ca piață, piele, piept, pieptene, piersic, picior. Prezența unor astfel de apelative, în care consoana inițială apare palatalizată, figurează în structura unor toponime şi a fost pusă în evidență prin cercetarea toponimiei din Câmpia Băileştiului (Oancă 1999, p. 88-92). În aceeaşi lucrare (p. 82-87) s-a urmărit şi prezența palatalizată a consoanei [p] în nume de familie precum Chele, Cheptănaru, Chetraru, Chistol, Chitaru, alături de numele de familie cu inițiala [p] nepalatalizată. În toate cazurile s-a menționat frecvența acestor nume de familie (câte persoane poartă numele respective, potrivit BDAR), pe județe, prilej de a constata cum se distribuie fenomenul palatalizării consoanei labiale $[p]$ prin intermediul numelor de familie. În cercetarea toponimică amintită am putut nota pronunțări ale apelativelor din structura unor toponime cu stadii diferite ale procesului de palatalizare: La crucea de Ph'atră (Segarcea), La Pk'etrărie (Cerăt), Fântâna de Fk'er (Balasan), Zġezuini (Măceşul de Sus). Astfel de pronunțări ale numelor topice caracterizează în mică măsură toponimia din Câmpia Băileștiului, care reprezintă sudul Olteniei.

În BDAR n-am identificat decât nume de familie cu inițiala [p] şi cu stadiul final de palatalizare (vezi Anexa). Numele de familie exprimat printr-un cuvânt s-a institutionalizat în Vechiul Regat în a doua jumătate a secolului al XIX-lea, acțiunea devenind obligatorie prin Legea asupra numelui din 1895. În celelalte regiuni româneşti, procesul de instituționalizare a numelui de familie s-a petrecut în a doua jumătate a secolului al XVIII-lea. „În Ardeal obligativitatea numelui de familie datează de la sfârşitul veacului al XVIII-lea, în urma unei dispoziții date de Împăratul Iosif al II-lea" (Paşca, 1936, p. 63). Cum numele de familie la români se transmite pe cale bărbătească de la o generație la alta, rezultă că formele sub care se prezintă aceste antroponime sunt mai vechi decât cele dintâi studii privitoare la acest fenomen fonetic. 
Din cercetarea numelor de familie perechi din Anexă, cu şi fără iniţiala palatalizată, putem aprecia că un rol important l-au jucat, în trecutul nu prea îndepărtat persoanele care redactau actele de stare civilă. Acestea aveau grade diferite de instrucție şcolară. Ofițerii de stare civilă din târguri erau mai instruiți decât aceia din mediul sătesc, cunoşteau forma nedialectală a numelui pe care îl consemnau în registrul de stare civilă. Comunicarea orală a naşterii unui copil, în mediul sătesc, cu precizarea numelui atribuit acestuia, era reținută de ofițerul de stare civilă şi notată, cel mai frecvent, aşa cum era pronunțat atât numele copilului, cât şi al părinților. Dacă aceştia erau cunoscuți printr-o poreclă sau un supranume, numele apărea în document în forma rostită. Numele de familie cuprinse în Anexă provin din supranume care îşi au originea în porecle (Piele, Peptine, Piper, Pistol, Pițigoi, Piciorea (derivat cu suf. -ea de la porecla Picior), în nume de agent (Peptanariu, Peptănaru, Pietrariu, Pietraru, Pioaru, Pitariu, Pitaru) şi în toponimul Piatra.

Cele patrusprezece perechi de nume de familie din Anexă, la care se adaugă numele Kele, în redactare maghiarizată, totalizează 18019 persoane. Dintre acestea, 7654 de persoane au numele de familie cu consoana inițială palatalizată, iar numele a 10365 de persoane nu prezintă această particularitate fonetică. Întrucât majoritatea studiilor privitoare la fenomenul palatalizării consoanelor labiale indică subdialectul moldovean ca reprezentativ pentru acest fapt de limbă, care caracterizează şi sudul Olteniei, potrivit unor studii întreprinse, am extras din Anexă numărul purtătorilor de nume de familie care prezintă consoana inițială palatalizată şi nepalatalizată în toate regiunile, cu județele alcătuitoare. Situația se prezintă astfel:

Număr de persoane cu nume de familie cu consoana inițială [p] palatalizată:

Moldova 5275: 1156-Bc, 230-Bt, 540-Gl, 665-Iş, 813-Nț, 136-Sv, 652-Vr, 861-Vs.

Muntenia 339: 43-Ag, 86-Br, 47-Bz, 18-Cl, 8-Db, 12-Gr, 37-Il, 75-Ph, 13-Tr.

Oltenia 68: 12-Dj, 20-Gj, 17-Mh, 10-Ot, 9-Vl.

Dobrogea 379: 351-Ct, 28-Tl.

Transilvania 709: 53-Ab, 11-Bn, 206-Bv, 44-Cj, 31-Cv, 131-Hd, 57-Hg, 142-Mş, 34-Sb.

Maramureş 48: 6-Mm, 42-Sm.

Crişana 128: 48-Ar, 76-Bh, $4-\mathrm{Sj}$.

Banat 167: 35-Cs, 132-Tm.

Bucureşti 541.

Număr de persoane cu nume de familie cu consoana inițială [p] nepalatalizată:

Moldova 1 345: 110-Bc, 109-Bt, 242-Gl, 277-Iş, 220-Nț, 200-Sv, 106-Vr, 81-Vs. 
Muntenia 3 158: 558-Ag, 41-Br, 202-Bz, 184-Cl, 191-Db, 202-Gr, 86-Il, 944-Ph, 750-Tr.

Oltenia 3 095: 625-Dj, 503-Gj, 174-Mh, 807-Ot, 986-Vl.

Dobrogea 282: 226-Ct, 56-Tl.

Transilvania 891: $52-\mathrm{Ab}, 13-\mathrm{Bn}, 191-\mathrm{Bv}, 54-\mathrm{Cj}, 28-\mathrm{Cv}, 201-\mathrm{Hd}, 13-\mathrm{Hg}$, 143-Mş, 196-Sb.

Maramureş 12: 1-Mm, 11-Sm.

Crişana 74: 44-Ar, 29-Bh, 1-Sj.

Banat 288: 115-Cs, 173-Tm.

Bucureşti 1220.

Această prezentare sintetică privind distribuția palatalizării consoanei inițiale [p], din numele de familie cuprinse în Anexă, corespunde punctului de vedere exprimat de Matilda Caragiu Marioțeanu (1975, p. 159): „Palatalizarea labialelor este un fenomen parțial în dacoromână, în sensul că nu apare pe întreg teritoriul şi nici la toate labialele în acelaşi grai. Astfel, labialele rămân nealterate, ca în limba literară, în graiurile munteneşti (centrale şi de vest), în graiul bănățean şi în jumătatea sudică a ariei crişene; ele se palatalizează în graiurile moldoveneşti, în graiul maramureşean, în jumătatea de nord a graiului crişean şi în graiurile munteneşti de est, parțial".

Având în vedere faptul că urmărim acest fenomen fonetic prin intermediul numelor de familie, trebuie să tinem seama de deplasările în teritoriu ale indivizilor, de schimbarea domiciliului datorită unor cauze sociale şi culturale, fapt care a dus la înregistrarea unor nume de familie acolo unde această particularitate fonetică nu este caracteristică. Un exemplu convingător este prezența în Moldova a numelor de familie care nu prezintă această particularitate fonetică (1345 de persoane, potrivit Anexei). Alt exemplu îl constituie diferența dintre ceea ce rezultă din statistica referitoare la această particularitate fonetică prezentă în sudul Olteniei şi în alte graiuri dacoromâne şi constatarea fenomenului ca urmare a anchetelor dialectale: „O arie palatalizată compactă apare în sud-vestul Olteniei, alta - mai restrânsă - la vest de București, una foarte întinsă - în nord-estul şi estul Munteniei, alta - în sudul Transilvaniei” (Caragiu, 1977, p. 164). Dezvoltarea în ultimii cincizeci de ani a unor importante centre industriale (în Transilvania în județele Braşov, Hunedoara, Mureş; în Muntenia: jud. Argeş, Buzău, Prahova; în județele din Oltenia) a atras forță de muncă provenită din zonele în care fenomenul palatalizării consoanelor labiale este caracteristic.

Cercetarea unor fapte de limbă prin intermediul antroponimelor, cu deosebire nume de familie, care s-au instituționalizat în a doua jumătate a secolului al XIX-lea şi au fost înregistrate în acte de stare civilă în forma comunicării orale, pune în evidență, cu ajutorul metodei de investigație onomastică geografia antroponimică, reprezentarea teritorială, pe unități administrative, a distribuției numelor de familie cu particularitatea amintită. 


\section{ANEX $\check{A}$}

Chele 592: O-5 (1-Dj, 4-Mh); M-17 (2-Ag, 4-Br, 10-Bz, 1-Cl); D-20 (16-Ct, 4-Tl); ML-479 (41-Bc, 62-Gl, 103-Iş, 223-Nț, 3-Sv, 9-Vr, 38-Vs); MR-17 (Sm); T-23 (1-Ab, 12-Bv, 2-Hd, 6-Mş, 2-Sb); CR-7 (1-Ar, 6-Bh); BNT-4 (2-Cs, 2-Tm); B-20.

Piele 878: O-260 (78-Dj, 25-Gj, 10-Mh, 54-Ot, 93-Vl); M-406 (95-Ag, 3-Br, 49-Bz, 3-Db, 45-Gr, 11-Il, 128-Ph, 72-Tr); D-12 (Cț); ML-20 (15-Gl, 2-Nț, 3-Vs); T-65 (1-Ab, 5-Bv, 2-Cj, 38-Hd, 5-Hg, 14-Sb); BNT-11 (2-Cs, 9-Tm); B-104.

Cheptanariu 135: M-1 (Il); D-2 (Cț); ML-111 (66-Bt, 27-Iş, 6-Nț, 10-Sv, 2-Vs); MR-1 (Mm); T-2 (Bv); BNT-4 (Tm); B-14.

Peptanariu 110: ML-95 (1-Bc, 2-Bt, 8-Iş, 26-Nț, 58-Sv); T-6 (Hd); CR-1 (Ar); B-8.

Cheptănaru 109: M-3 (1-Bz, 1-Il, 1-Ph); D-2 (1-Cț, 1-Tl); ML-92 (54-Bc, 3-Bt, 1-Gl, 10-Nt, 1-Sv, 9-Vr, 14-Vs); T-12 (6-Ab, 6-Hd).

Peptănaru 113: O-5 ( 4-Dj, 1-Gj); M-26 (5-Br, 6-Bz, 3-Db, 3-Gr, 5-Ph, 4-Tr); D-3 (Tl); ML-68 (23-Bc, 24-Gl, 14-Nt, 7-Sv); T-4 (Bv); BNT-2 (Cs); B-5.

Cheptine 117: M-12 (5-Br, 7-Cl); D-3 (Tl); ML-82 (32-Bc, 3-Gl, 15-Iş, 1-Nt, 31-Vr); T-14 (Bv); B-6.

Peptine 144: O-13 (4-Ot, 9-Vl); ML-122 (24-Bc, 76-Gl, 2-Iș, 7-Nț, 6-Vr, 7-Vs); T-8 (Bv); B-1.

Chetrariu 210: O-6 (5-Gj, 1-Ot); M-7 (6-Ag, 1-Br); D-4 (Ct)); ML-144 (12-Bc, 51-Bt, 1-Gl, 15-Iş, 15-Nț, 48-Sv, 2-Vs); MR-8 (Sm); T-11 (1-Ab, 6-Bv, 1-Cj, 3-Hd); CR-4 (Ar); BNT-4 (Tm); B-22.

Pietrariu 100: O-27 (Vl); M-10 (9-Ag, 1-Db); ML-42 (13-Bt, 26-Sv, 3-Vs); BNT-11 (1-Cs, 10-Tm); B-10.

Chetraru 293: O-2 (Dj); M-13 (5-Br, 4-Cl, 2-Gr, 2-Ph); D-15 (Cț); ML-221 (90-Bc, 1-Bt, 22-Gl, 21-Iş, 17-Nț, 33-Sv, 4-Vr, 33-Vs); T-27 (20-Bv, 6-Hd, 1-Mş); B-15.

Pietraru 709: O-171 (13-Gj, 16-Ot, 142-Vl); M-296 (26-Ag, 63-Bz, 14-Cl, 18-Db, 3-Gr, 65-Il, 107-Ph); D-9 (6-Cț, 3-Tl); ML-72 (12-Bc, 7-Bt, 22-Gl, 8-Iş, 11-Nț, 7-Vr, 5-Vs); MR-5 (Sm); T-27 (3-Bv, 1-Cj, 3-Cv, 3-Hd, 1-Mş, 16-Sb); BNT-5 (2-Cs, 3-Tm); B-124.

Chetreanu 542: O-12 (1-Gj, 10-Mh, 1-Vl); M-9 (4-Ag, 3-Br, 2-Ph); D-15 (Cț); ML-414 (79-Bc, 54-Bt, 16-Gl, 14-Iş, 73-Nț, 5-Sv, 144-Vr, 29-Vs); MR-1 (Mm); T-38 (1-Ab, 21-Bv, 4-Cj, 7-Hd, 2-Hg, 1-Mş, 2-Sb); CR-1 (Ar); BNT-7 (1-Cs, 6-Tm); B-45.

Pietreanu 559: O-73 (3-Gj, 34-Ot, 36-Vl); M-350 (33-Ag, 5-Cl, 2-Db, 16-Gr, 5-Ph, 289-Gr); D-6 (Ct)); ML-5 (4-Sv, 1-Vs); MR-1 (Mm); T-9 (4-Bv, 5-Hd); CR-9 (Bh); BNT-6 (Tm); B-100.

Chiciorea 114: O-2 (Dj); M-11 (4-Br, 7-Il); ML-81 (29-Bc, 2-Gl, 47-Vr, 3-Vs); T-1 (Hd); B-19. 
Piciorea 597: O-18 (2-Dj, 16-Vl); M-500 (4-Bz, 494-Ph, 2-Tr); D-20 (17-Cț, 3-Tl); ML-11 (4-Bc, 3-Nț, 1-Sv, 3-Vs); MR-5 (Sm); T-15 (14-Bv, 1-Cj); B-28.

Chioaru 177: O-7 (Gj); M-11 (8-Ag, 3-Db); D-24 (23-Ct, 1-Tl); ML-76 (36-Bc, 4-Bt, 13-Iş, 7-Nț, 8-Sv, 7-Vr, 1-Vs); T-12 (5-Bv, 2-Hd, 5-Sb); BNT-5 (Cs); B-42.

Pioaru 151: O-2 (Vl); M-129 (9-Ag, 1-Cl, 93-Db, 4-Il, 22-Ph); ML-2 (Vr); T-12 (2-Bn, 6-Bv, 4-Sb); B-6.

Chiper 3902: O-27 (7-Dj, 2-Gj, 3-Mh, 9-Ot, 6-Vl); M-198 (10-Ag, 50-Br, 36-Bz, 6-Cl, 5-Db, 8-Gr, 28-Il, 53-Ph, 2-Tr); D-266 (262-Cț, 4-Tl); ML-2508 (654-Bc, 23-Bt, 370-Gl, 224-Iş, 187-Nț, 26-Sv, 377-Vr, 647-Vs); MR-1 (Sm); T-463 (36-Ab, 11-Bn, 110-Bv, 35-Cj, 22-Cv, 88-Hd, 8-Hg, 134-Mss, 19-Sb); CR-41 (35-Ar, 2-Bh, 4-Sj); BNT-71 (20-Cs, 51-Tm); B-291.

Piper 599: O-96 ( 42-Gj, 53-Ot, 1-Vl); M-115 (26-Ag, 14-Br, 2-Bz, 6-Db, 4-Gr, 63-Tr); D-11 (6-Cț, 5-Tl); ML-4 (Bc); MR-1 (Sm); T-306 (44-Ab, 1-Bv, 59-Cj, 47-Hd, 4-Hg, 138-Mş, 13-Sb); CR-19 (Ar); BNT-2 (Tm); B-45.

Chistol 489: O-7 (5-Gj, 2-Vl); M-33 (13-Ag, 3-Br, 2-Gr, 4-Il, 11-Tr); D-2 (Cț); ML-398 (5-Bc, 12-Bt, 1-Gl, 130-Iş, 238-Nț, 12-Vs); T-29 (8-Ab, 7-Bv, 9-Hd, 5-Sb); CR-1 (Ar); BNT-7 (Tm); B-12.

Pistol 2303: O-822 (86-Dj, 201-Gj, 113-Mh, 196-Ot, 226-Vl); M-415 (35-Ag, 10-Br, 23-Bz, 87-Cl, 9-Db. 61-Gr, 3-Il, 24-Ph, 163-Tr); D-129 (104-Ct, 25-Tl); ML-415 (13-Bc, 58-Bt, 24-Gl, 156-Iş, 14-Nț, 35-Sv, 81-Vr, 34-Vs); T-55 (7-Ab, 19-Bv，3-Cv，16-Hd，10-Sb); CR-24 (13-Ar，10-Bh，1-Sj); BNT-49 (14-Cs, 35-Tm); B-394.

Chitariu 121: D-2 (Cț); ML-109 (5-Bc, 13-Bt, 55-Iş, 7-Nț, 1-Sv, 28-Vs); T-3 (Bv); B-7.

Pitariu 314: O-1 (Dj); M-8 (1-Ag, 3-Db, 1-Gr, 3-Ph); D-4 (2-Cț, 2-Tl); ML-167 (1-Bc, 11-Bt, 20-Gl, 49-Iş, 55-Nț, 28-Sv, 3-Vs); T-116 (3-Ab, 3-Cj, 23-Hd, 4-Mş, 83-Sb); BNT-12 (5-Cs, 7-Tm); B-6.

Chitaru 330: M-24 (11-Br, 3-Il, 10-Ph); D-19 (4-Cț, 15-Tl); ML-229 (42-Bc, 3-Bt, 47-Gl, 48-Iş, 13-Nț, 24-Vr, 52-Vs); T-9 (5-Bv, 4-Hd); CR-1 (Ar); BNT-3 (1-Cs, 2-Tm); B-45.

Pitaru 711: O-170 (90-Dj, 31-Gj, 7-Mh, 27-O t, 15-Vl); M-108 (7-Ag, 6-Bz, 9-Cl, 18-Db, 46-Ph, 22-Tr); D-23 (12-Cț, 11-Tl); ML-236 (19-Bc, 18-Bt, 8-Gl, 54-Iş, 79-Nț, 41-Sv, 1-Vr, 16-Vs); T-15 (2-Ab, 4-Bv, 2-Hd, 3-Mş, 4-Sb); CR-6 (Bh); BNT-54 (22-Cs, 32-Tm); B-99.

Chițigoi 127: ML-109 (77-Bc, 15-Gl, 16-Nț, 1-Sv); T-16 (3-Bv, 2-Cj, 7-Cv, 1-Hd, 3-Sb); B-2.

Pițigoi 2667: O-1437 (364-Dj, 187-Gj, 44-Mh, 423-Ot, 419-Vl); M-851 (317-Ag, 9-Br, 49-Bz, 68-Cl, 35-Db, 69-Gr, 3-Il, 110-Ph, 192-Tr); D-69 (63-Ct,, 6-Tl); ML-86 (9-Bc, 53-Gl, 9-Nț, 9-Vr, 6-Vs); T-96 (3-Ab, 14-Bv, 12-Cj, 20-Hd, 1-Mş, 46-Sb); CR-14 (11-Ar, 3-Bh); BNT-67 (47-Cț, 20-Tm); B-47.

Kele 212 (grafie ungurească): D-5 (Cț); MR-20 (4-Mm, 16-Sm); T-51 (2-Cj, 2-Cv, 2-Hd, 44-Hg, 1-Sb); CR-73 (5-Ar, 68-Bh); BNT-62 (6-Cs, 56-Tm); B-1. 


\section{BIBLIOGRAFIE}

BDAR = Baza de date antroponimice a României, constituită la Laboratorul de cercetări onomastice de la Facultatea de Litere a Universității din Craiova în 1994, pe baza datelor puse la dispoziție pe suport electronic de Inspectoratele județene de poliție, Seviciul de evidență a populației.

Caragiu 1975 = Matilda Caragiu Marioțeanu, Compendiu de dialectologie română (nord- şi suddunăreană, Bucureşti, Editura Ştiințifică şi Enciclopedică.

Caragiu 1977 = Matilda Caragiu Marioțeanu, Ştefan Giosu, Liliana Ionescu-Ruxăndoiu. Romulus Todoran, Dialectologie română, București, Editura Didactică şi Pedagogică.

Ionică 1973 = Ion Ionică, Palatalizarea labialelor în Oltenia, în „Fonetică şi dialectologie”, vol. VIII, Bucureşti, Editura Academiei, 1973.

Oancă 1998 = Teodor Oancă, Geografie antroponimică. Metodă şi aplicații, Craiova, Editura de Sud.

Oancă 1999 = Teodor Oancă, Onomastică şi dialectologie, Craiova, Fundația Scrisul Românesc.

Paşca 1936 = Ştefan Paşca, Nume de persoane şi nume de animale în Țara Oltului, Bucureşti, 1936.

\section{ANTHROPONYMS WITH THEIR INITIAL CONSONANT [P] \\ PALATALIZED}

\section{ABSTRACT}

The paper points out the territorial distribution of the surnames whose initial $[\mathrm{p}]$ is either palatalized or not (Chele - Piele, Cheptine - Peptine, Chistol-Pistol etc.). Our research confirms the results of the dialectal surveys focused on the occurrence of this linguistic phenomenon with common nouns.

Facultatea de Litere Universitatea din Craiova 